\title{
Military-funded research is not unethical
}

\section{The key is to ensure that it is the military rather than the scientists who are regulated.}

Sir - Of particular interest in your News Feature "Remote control" on the state of neuroengineering research (Nature $423,796-798 ; 2003)$ is the discussion of the ethical issues and views attributed to Professor Martha Farah, that any researcher who accepts funding from the US Department of Defense without agreeing with the goals of the programme compromises his or her ethics.

First, the goal of the programme (www. darpa.mil/dso/thrust/biosci/bim.htm) is the development of new computational and microsystem tools to study biological systems. It is hard to see how these goals pose ethical problems for researchers. However, looking beyond the officially stated goals of the programme to the broader issue of military funding, your News Feature says that some scientists feel using money from the military is ethically problematic. This view ignores the historical and social context of military research. If having a well-regulated US military is both necessary and ethically sound, given the current state of the world, then there is no reason to believe that supporting this capacity in the form of basic research poses an ethical dilemma. The key is to ensure that it is the military who remain 'wellregulated' rather than the basic scientists.

The main argument against these ethical concerns, however, is the nature of knowledge itself, which has neither good nor evil attributes. Currently, the Defense Advanced Research Projects Agency (DARPA) is funding basic-science researchers in a nonclassified capacity precisely because the principles on which a robust neuralcontrol signal might be based are not yet known. Only the real-world application of such natural principles, once discovered, will enable good or evil to occur. In the case of neuroengineering research, the knowledge being generated clearly has the potential for a large positive impact on society. Decoding neural-control signals from paralysed or locked-in patients could allow them to regain physical function or the ability to communicate.
Many technologies funded by the US military have led to positive and even revolutionary changes in society. As a case in point, the Internet was originally conceived and funded by the previous incarnation of DARPA. The immense positive social impact of the Internet makes it clear that the presence of DARPA funding does not necessarily provide an accurate indication of how technology created from basic research will be used, and as such, has no relevance to ethical debate. The neuroengineering community serves the best interests of society quite well and we encourage a thorough and open debate of the applications built upon neuroengineering research.

\section{Daniel S. Rizzuto, Boris Breznen,} Bradley Greger

California Institute of Technology

Division of Biology, MC 216-76,

Pasadena, California 91125, USA

Although none of the authors is currently a direct recipient of DARPA grants, each has used DARPA funds in the past.

\section{Military: brain machine could benefit millions}

Sir - Your News Feature "Remote control" (Nature 423, 796-798; 2003) misrepresented some aspects of the brain-machine interface programme funded by the US Defense Advanced Research Projects Agency (DARPA). The DARPA programme is basic research, defined by the Department of Defense as "systematic study directed toward greater knowledge or understanding of the fundamental aspects of phenomena and of observable facts without specific applications toward processes or products".

DARPA recognizes that the development of new brain-machine interfaces will have restorative applications in the biomedical community. We embrace those advances as important technological goals for the future, and have funded projects like those you describe in your feature because of these key medical missions. We appreciate the tremendous benefit this technology will have to both defence personnel and civilians, especially the millions of military veterans who could profit from this work.

Your feature is inaccurate in describing how proposals were selected for the programme. Proposals were solicited from the research community in an open competition, and those funded were selected based on a review by a panel of experts. DARPA also does not as a practice threaten insecurity. Our programmes are milestone-driven, as that is a way to ensure the best use of taxpayer dollars, but we are sensitive to working with academic institutions, and do our best to ensure stability in graduate education.

I also believe you have inaccurately advocated an ethical position in your Editorial "Silence of the Neuroengineers" (Nature 423, 787; 2003). Although it is important to discuss the ethics of neuroscience research, the premise of your editorial and ethical argument is based on an inaccurate portrayal of DARPA funding. The reluctance of DARPA investigators to speak about the narrow vision of brainmachine interfaces that you portrayed relates to the basic-research nature of the DARPA funding rather than their ethics. The editorial states "Simply taking DARPA's money, and citing possible medical benefits, is not enough". Indeed, if these investigators succeed in their outstanding research, this should be more than enough. A sound ethical argument should also consider the opportunity lost for the millions of people who might benefit from important restorative benefits if the DARPA programme did not fund the work and the possibility of a new generation of brain-machine interfaces did not emerge.

Alan Rudolph

Defence Science Office, DARPA, 3701 North Fairfax Drive, Arlington, Virginia 22203, USA

\section{Authorities should note sponsorship-results link}

Sir - According to your survey of senior scientists in Germany (Nature 424, 117; 2003 ), $80 \%$ feel that misconduct is a major problem in clinical research.

This outcome is consistent with a recent study published in the Journal of the American Medical Association (JAMA), which reveals a significant association between industry sponsorship and proindustry results (J. E. Bekelman, Y. Li \& C. P. Gross, J. Am. Med. Assoc. 289, 454-465; 2003). The JAMA analysis concludes that industry-sponsored studies are nearly four times more likely to reach pro-industry conclusions than are studies that are not industry-sponsored.

Obviously this is a major problem. The JAMA authors say "all investigators and sponsors undertaking human participant research should not only fully disclose the nature and extent of their relationships but also make available all research results from completed clinical trials in a comprehensive, publicly accessible registry".

In my view, it should be mandatory for health authorities to consider the potential influence of industry sponsorship on the results of clinical studies during the approval process.

Leoluca Criscione

Kirchstrasse 15, 4313 Moehlin, Switzerland 